\title{
Melanoptysis as a complication of fibreoptic bronchoscopy
}

\author{
M.J. Mena, M.J. Rodriguez-Nieto, M. Gómez, J. Flandes, R. Melchor
}

\begin{abstract}
Melanoptysis as a complication of fibreoptic bronchoscopy. M.J. Mena, M.J. RodriguezNieto, M. Gómez, J. Flandes, R. Melchor. CERS Journals Ltd 1998.

ABSTRACT: The case is presented of a coal miner with bilateral masses of progressive massive fibrosis, who developed acute cavitation following fibreoptic bronchoscopy and biopsies. Indeed, immediately upon bronchoscopy with transbronchial biopsy, there was expectoration of abundant melanoptysis. Three days later, the chest radiograph showed a cavity and the patient again coughed up black material, in the context of pulmonary infection. One week later, there was complete emptying of the conglomerate mass. To the authors' knowledge, this is the first reported case of a conglomerate mass of progressive massive fibrosis which cavitated as a result of bronchoscopy.
\end{abstract}

Eur Respir J 1998; 12: 993-995.
Servicio de Neumología, Fundación Jiménez Díaz, Madrid, Spain

Correspondence: R. Melchor, Servicio de Neumología, F.J.D., Avda. Reyes Católicos No. 2, 28040 Madrid, Spain, Fax: 34 915494567

Keywords: Adverse effects, bronchoscopy, coal miner, iatrogenic complications, melanoptysis, pneumoconiosis

Received: January 151998 Accepted after revision May 71998
Up to one-third of coal miners with pneumoconiosis may develop progressive massive fibrosis (PMF) of the lung. Masses of PMF may eventually cavitate owing to ischaemia or other causes, such as tuberculosis, fungal infections or neoplasia [1]. An additional cause of cavitation of PMF masses is described here, namely fibreoptic bronchoscopy with transbronchial biopsies.

\section{Case study}

A $57 \mathrm{yr}$ old male was admitted to hospital because of chest pain. He had been a coal-cutting worker in anthracite mines for $12 \mathrm{yrs}$ in the province of Leon (north-western Spain) until the age of $32 \mathrm{yrs}$, when he was diagnosed with pneumoconiosis. He then stopped working as a miner and was never again exposed to other work-related risk factors for lung diseases. He continued smoking 20 cigarettes.day ${ }^{-1}$ until the age of 42 yrs. The patient met the criteria for chronic bronchitis and had dyspnoea on exertion.

He presented to the emergency room complaining of recent pleuritic chest pain in his right hemithorax and a dry cough. No other symptoms were present. He was eupnoeic and lung sounds were diffusely diminished. The remainder of the physical examination was normal. The chest radiograph showed bilateral small round opacities (p/q, 1/1, right upper lobe; p/q 2/2 left upper lobe; p/p 0/1 left middle lobe and no lesions (NL) for the rest of lung divisions) and masses measuring $9 \times 6 \mathrm{~cm}$ (right upper lobe), $6 \times 5 \mathrm{~cm}$ (right lower lobe) and $3 \times 4 \mathrm{~cm}$ (left lower lobe), i.e. category $\mathrm{C}$ (fig. 1). The patient was given paracetamol and became asymptomatic 2 days later.

Comparison with a chest radiograph taken 4 yrs earlier showed that the mass in the right upper lobe had increased substantially during that period. Fibreoptic bronchoscopy was thus advocated, in order to rule out bronchial or lung carcinoma. Anthracotic spots were visualized at all levels of the bronchial tree. Blind transbronchial biopsies

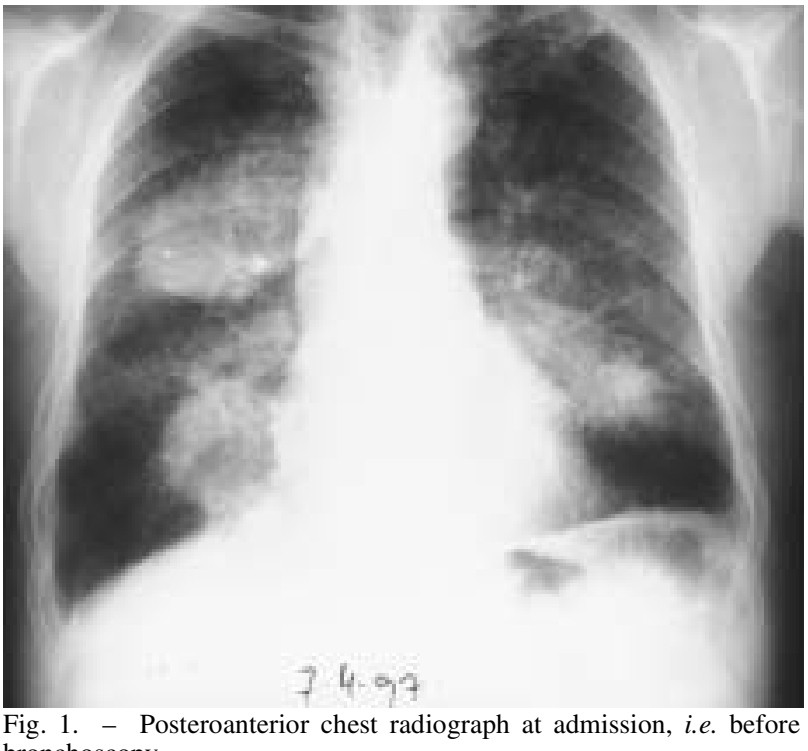
bronchoscopy.

and bronchial brushing were performed in segments 3 and 6 of the right lung. Immediately after the samples were taken, about $250 \mathrm{~mL}$ of black liquid material was expectorated. The microbiological studies, including a search for Mycobacteria and fungi, and cytology of the samples were negative. Histopathological examination of the biopsy material (not shown) showed pulmonary fibrosis and silicoanthracosis, but no malignant cells.

Three days later, the patient returned with chest pain and a dry cough. He had not produced any more black sputum since the bronchoscopy was performed. His temperature was $38^{\circ} \mathrm{C}$ and wheezes and ronchi were heard. The remainder of the examination was unchanged. The patient was admitted; previously he had been an outpatient. The white blood cell $(\mathrm{WBC})$ count was $21 \times 10^{9}$ cells $\cdot \mathrm{L}^{-1}$ with 


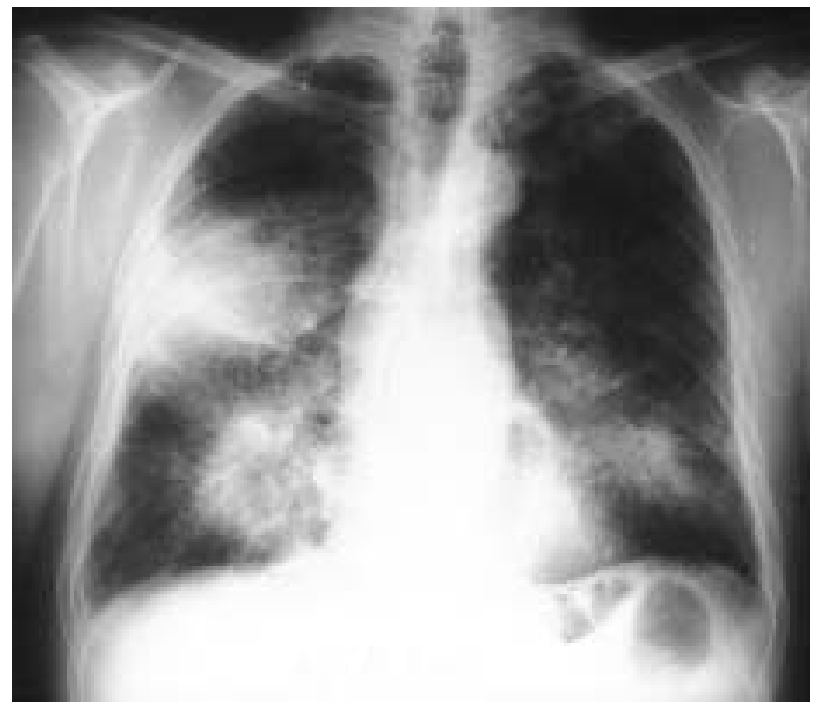

Fig. 2. - Posteroanterior radiograph after bronchoscopy. Note a small cavitation in the posterior segment of the right-upper lobe.

$80 \%$ neutrophils and the erythrocyte sedimentation rate (ESR) was $74 \mathrm{~mm}$ in $1 \mathrm{~h}$. Red blood cells, platelets and routine biochemical tests were all normal. Blood cultures were negative. A small cavitation was seen in the right mass of PMF (the site from which the biopsy samples had been taken) (fig. 2). An arterial blood sample taken while the patient was breathing room air showed a $\mathrm{pH}$ of 7.50, arterial oxygen tension $\left(\mathrm{Pa}_{\mathrm{a}} \mathrm{O}_{2}\right)$ of $8.1 \mathrm{kPa}$ and arterial carbon dioxide tension $\left(\mathrm{Pa}_{\left.\mathrm{a}, \mathrm{CO}_{2}\right)}\right.$ of $3.5 \mathrm{kPa}$. On the first day of hospitalization he again started to cough up black material, with a maximum of $200 \mathrm{~mL} \cdot$ day $^{-1}$, and a cumulated amount of $1,500 \mathrm{~mL}$ in 7 days. He was given amoxilinclavulanic acid. He became afebrile and no longer expectorated during his last 4 days in the hospital. The chest radiograph showed a progressive enlargement of the size of the cavity, which had a spindle-shaped configuration (fig. 3). Three months after discharge, the patient was asymptomatic and no further episode of melanoptysis has occurred. The cavity was slightly reduced in size on the last chest radiograph.

\section{Discussion}

This study reported on what the authors believe to be the first published case in which a blind transbronchial lung biopsy procedure led to cavitation of a PMF mass with melanoptysis, in a patient with coal-worker's pneumoconiosis.

PMF is defined as a focus of irregular fibrosis and pigment deposition $>1 \mathrm{~cm}$ in diameter, with necrotic tissue, cholesterol clefts and inflammatory cells often present [1]. According to some authors, up to one-third of patients with pneumoconiosis progress to PMF [2, 3].

There is little correlation between symptoms and the radiographic category of pneumoconiosis [1]. Lesions of PMF can be unilateral, but far more often they are bilateral and affect predominantly the posterior segments of the upper lobes or the superior segment of the lower lobes [1]. Both upper and lower zones were involved in the present case. a)

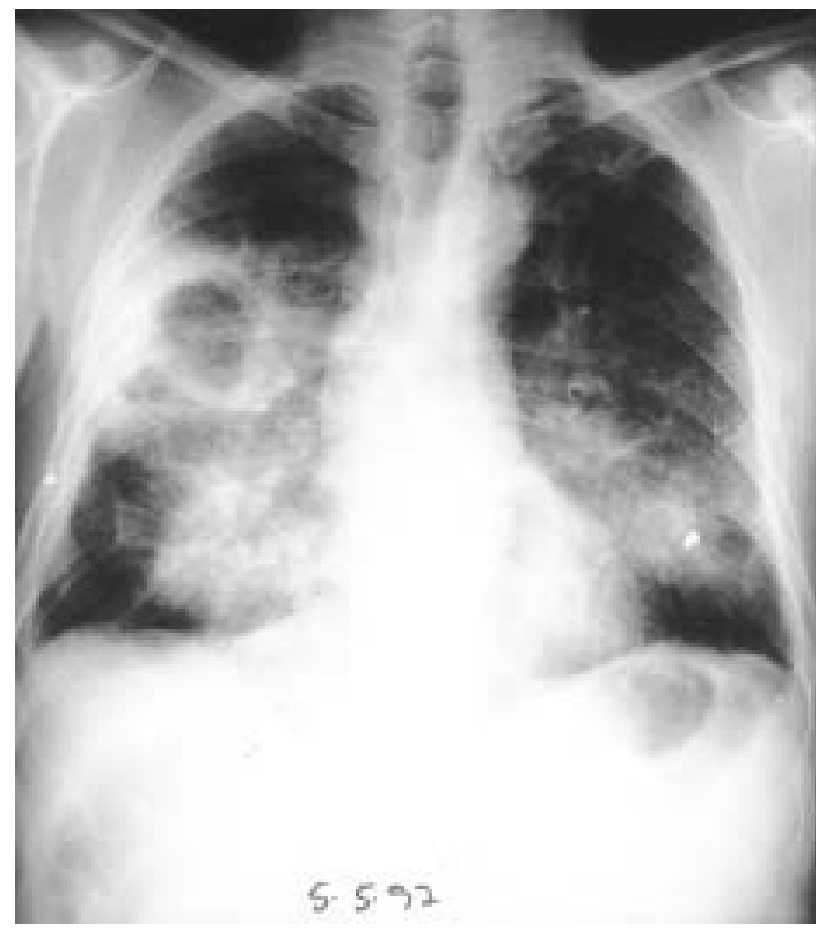

b)

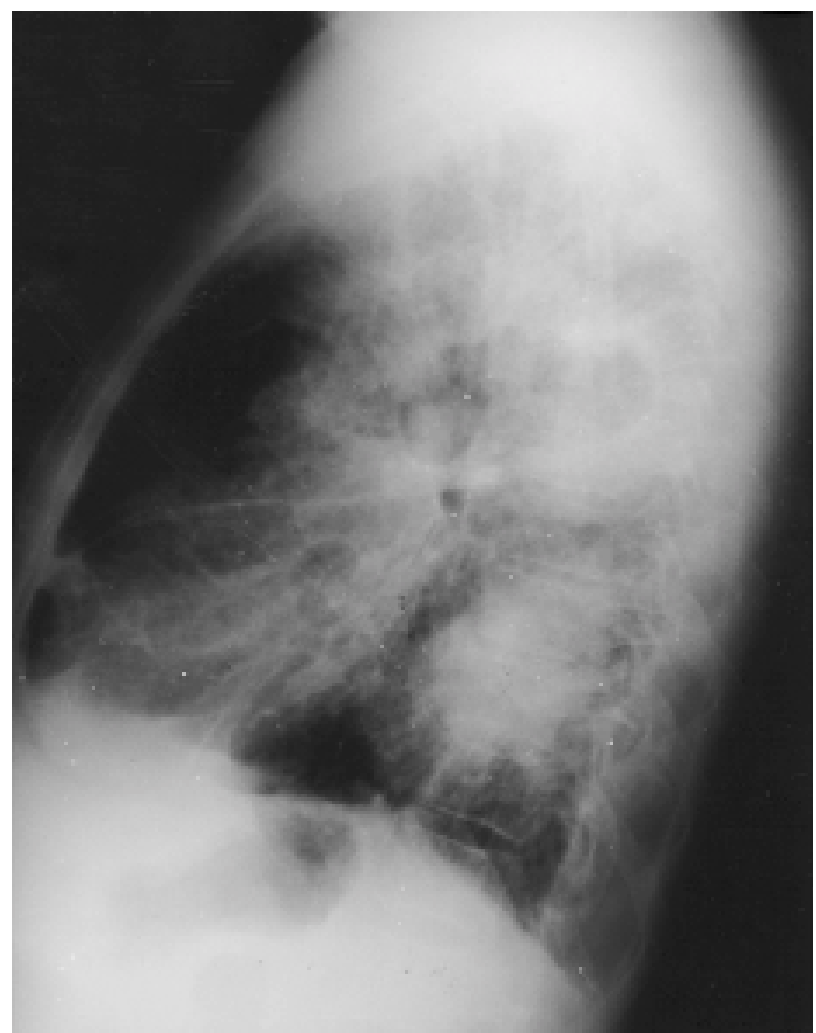

Fig. 3. - a) Posteroanterior and b) lateral radiographs at the time of discharge. The spindle configuration can be seen.

The conglomerates or masses of PMF may eventually cavitate [1]. Cavitation is thought to be secondary to ischaemia and subsequent necrosis $[1,4]$. This is supported by the fact that vascular obliteration is a common histological feature in PMF masses and avascular zones can be 
demonstrated by lung perfusion scanning [5]. Cavitation has also been reported in association with tuberculous superinfection, anaerobic infections, Caplan's syndrome and neoplasms $[1,4,6]$. Although understandable, cavitation of PMF masses has not yet been observed following bronchoscopy.

When a conglomerate mass cavitates, several patterns may be seen on the chest radiograph. The anatomic configuration creates an opacity with a characteristic shape, in that it is less dense on one projection than on the other [7]. This can be used to distinguish PMF masses from pulmonary carcinoma, the borders of which tend to be less well defined and which typically have a more spherical shape [1]. The patient under discussion presented with an enlarged conglomerate on one side. Bronchoscopy was advocated to rule out carcinoma and the cavitation appeared following this procedure, especially following blinded biopsies, which were presumably taken within the mass.

Melanoptysis, ethymologically the expectoration of black material, contains coal and is the clue symptom of PMF cavitation. It can also be observed in coal miners with simple pneumoconiosis, i.e. who do not have PMF [8, 9]. The amount is then usually minor and not massive, as in the case presented here. Unusual causes of melanoptysis other than exposure to coal have been reported in the context of freebase cocaine smoking [10], malignant melanoma of the lung [11] and pulmonary aspergilloma caused by Aspergillus niger [9].

Complications following fibreoptic bronchoscopy include pneumonia, lung abscess and pulmonary haemorrhage [12]. No cases were found in which a PMF mass underwent cavitation following bronchoscopy, whether it was associated with transbronchial biopsy or not. Blind transbronchial lung biopsy, rather than simple bronchoscopy, was believed to be the responsible step in the present patient's complication. Bronchoscopy-related infection, as suggested by the patient's symptoms a few days after the procedure, may have been a contributory factor. Although it cannot be proved, it was believed that blind transbronchial lung biopsy in the vicinity of fibrotic masses may lead to effraction and cavitation, regardless of their aetiology. Accordingly, endobronchial procedures in patients with masses resulting from silicosis should also be approached carefully.
In conclusion, effraction of a mass of progressive massive fibrosis can occur following bronchoscopy and transbronchial lung biopsy leading to melanoptysis. Accordingly, extreme care should be taken if bronchoscopy is performed in patients with progressive massive fibrosis masses and more so if a blind transbronchial lung biopsy is planned.

\section{References}

1. Fraser RS, Paré JAP, Fraser RG, Paré PD. Synopsis of Diseases of the Chest. Philadelphia, PA, W.B. Saunders, 1994.

2. Morgan WKC. Respiratory disease in coal miners. JAMA 1975; 231: 1347-1348.

3. Davies D. Disability and coal workers' pneumoconiosis. BMJ 1974; ii: 652-655.

4. Palacios A, Gallego B, Drobnic S, Vidal R. Melanoptisis y signo del semáforo en la cavitación de la fibrosis masiva progresiva antracótica. Arch Bronconeumol 1990; 26: 131-133.

5. Seaton A, Lapp NL, Chang CEJ. Lung perfusion scanning in coal workers pneumoconiosis. Am Rev Respir Dis 1971; 103: 338-349.

6. Haro M,Vizcaya M, Sánchez E, Coloma R, Loeches N. Melanoptisis paroxística secundaria a la cavitación de un conglomerado neumoconiótico pulmonar. Arch Bronconeumol 1996; 32: 199-201.

7. Williams JL, Moller GA. Solitary mass in the lands of coal miners. Am J Roentgenol 1973; 117: 765-770.

8. Mosquera JA. Massive melanoptysis, a serious unrecognized complication of coal worker's pneumoconiosis. Eur Respir J 1988; 1: 766-768.

9. Haro M, Nuñez A, González L, Vizcaya M. Black sputum and progressive cavitary lung lesion in a coal miner. Chest 1997; 111: 808-809.

10. Tashking D, Gorelick D, Khalsa ME, et al. Respiratory effects of cocaine freebasing among habitual cocaine users. J Addict Dis 1992; 5: 285-294.

11. Eide J. Pathogenesis of generalized melanosis with melanuria and melanoptysis secondary to malignant melanoma. Histopathology 1981; 5: 285-294.

12. Borchers S, Beamis J. Flexible bronchoscopy. Chest Surg Clin North Am 1996; 6: 169-192. 